\title{
O LUGAR DA EXPERIÊNCIA AFETIVA NA GÊNESE DOS PROCESSOS DE SUBJETIVAÇÃO
}

\author{
Carlos Augusto Peixoto Junior \\ Márcia Arán
}

Resumo: Dada a atualidade e a importância dos afetos na gênese dos processos de subjetivação, este artigo tem como objetivo central discutir as teses formuladas por Daniel Stern, autor que vem se dedicando nos últimos anos a observações minuciosas dos processos primários de subjetivação do infante, prestando uma atenção especial ao tema da experiência afetiva. Partindo de uma localização dos afetos em sua teoria, passamos a uma discussão a propósito da forma temporal dos sentimentos no contexto das relações interpessoais, para então analisarmos dois dos principais conceitos formulados por ele, quais sejam, os de afeto de vitalidade e sintonia afetiva. Ao longo desta discussão também serão contemplados outros temas relevantes, tais como as noções de interação afetiva, empatia e comunicação emocional.

Palavras-chave: Afeto. Subjetivação. Sintonia. Vitalidade.

\section{Introdução}

Não é de hoje que a temática do afeto vem despertando o interesse de diferentes teóricos que voltaram seus estudos para os âmbitos da vida e da existência humana. Desde a aurora da modernidade, com Espinosa e sua ênfase na potência 
do afeto, e mais tarde com os primeiros teóricos da psicanálise, a afetividade tem sido um importante objeto de investigação para o pensamento moderno. No entanto, é fácil perceber que a partir dos anos setenta a reflexão sobre o afeto penetrou mais profundamente na cultura, transbordando amplamente os círculos restritos dos debates filosóficos e psicanalíticos. Etólogos, psicólogos de todas as tendências e biólogos voltaram-se, cada um em seu domínio, para o estudo de suas formas e processos, buscando dar maior precisão teórica a suas funções. Nos EUA, por exemplo, Antonio Damásio, para citar apenas um dos trabalhos referenciais mais midiáticos dos últimos anos, com sua denúncia do Erro de Descartes, recolocou a questão do afeto no centro da biologia humana, renovando assim a abordagem, durante muito tempo apenas referencial, de Darwin e de seu Tratado das emoções. Vários "observadores" e clínicos da primeira infância, por sua vez, também se dedicaram ao estudo do lugar e da importância da vida afetiva partilhada na organização primária da subjetividade, assim como na regulação primeira da relação que une e diferencia o bebê humano e seus primeiros objetos. Dado o lugar destacado ocupado pelo afeto nesse contexto, vejamos, a título de introdução para o presente trabalho, como poderíamos tentar definir o que seria, em termos gerais, o afeto.

Aquilo que denominamos com essa palavra pode se referir tanto ao que nos é dado vivenciar conscientemente em certas circunstâncias, ou seja, um estado subjetivo que "sentimos", como também pode se referir àquilo que não se sente de modo direto, mas que se entrevê ou infere no comportamento alheio e, menos facilmente, no nosso. Com a finalidade de evitar a ambiguidade contida nessa dupla referência, seria possível usar no primeiro caso o termo sentimento, mesmo que prevaleça no senso comum um certo uso do termo"sentimento inconsciente",e dar ao "afeto" um significado mais geral. Isso poderia ser extraído da própria etimologia da palavra: afeto, particípio passado de afficere, parece indicar claramente o caráter passivo da experiência subjetiva em questão, ou então o fato de que esta foge ao controle das nossas intenções e desejos. Outros termos aparentados também possuem esse significado etimológico: emoção (emotum), paixão (patior), indicando como experiências semelhantes "atuam em nós", indo além da vontade e da consciência.

Os fenômenos afetivos foram diversamente definidos e subdivididos. A mais conhecida e discutida distinção é aquela entre sentimentos e emoções, ainda que outros fenômenos tenham sido diversamente elencados e diferenciados. Mais rápida e claramente que na cognição, evidenciou-se o caráter processual do afeto, mas tal processualidade logo se mostrou muito mais fugidia e complexa e, sobretudo, mais evidentemente subtraída à consciência do sujeito. $O$ termo, muito mais antigo, de paixão, indica claramente um conceito de algo experimentado - padecido - pelo sujeito, e obscuro à sua consciência. 
Segundo Imbasciati, a denominação que usamos para indicar os vários estados afetivos tem uma clara referência consciencialista: termos como cólera, aborrecimento, desgosto, tristeza, remetem-nos imediatamente àquilo que o sujeito está em condições de sentir e de contar sobre si mesmo.

Todavia, desde o início esteve claro para a Psicologia o quanto os afetos escapavam à consciência que os individualizava e o quanto se devia supor, buscando um modo de investigar toda a processualidade anterior ao epifenômeno consciente. Não existem somente os afetos experimentados e referidos, mas também, e em quantidade maior, aqueles inferidos. (Imbasciati, 1998, p. 123)

Um caminho na direção de um maior esclarecimento a propósito dos afetos foi o de indagar os estados biológicos a eles associados, muitas vezes de modo evidente: daí a individualização das "emoções" e do seu estudo psicofisiológico. Mas a via biológica não resolvia, senão em parte e em uma só direção, o problema de uma investigação puramente psicológica sobre os afetos na sua acepção mais ampla, que fosse além do epifenômeno consciente e verbalizado. Nisso, várias escolas se subdividiram e se ramificaram em suas diferentes metodologias e teorizações (Plutchik \& Kellermann, 1985).

Diante dessas dificuldades, o estudo de crianças pôs em relevo a limitação e a necessidade da diferenciação entre afeto e cognição; as crianças tornam completamente evidentes os afetos, e certamente não através da introspecção: elas mostram que os afetos são a sua forma de cognição, do mundo e de si mesmas, e mais ainda quanto menor for a criança. Os estudos etológicos, assim como os psicanalíticos, chegam à mesma conclusão, tanto em relação às crianças quanto aos animais: o afeto é uma forma primitiva de cognição'.

Considerando a atualidade e a importância dessas questões, gostaríamos de discutir neste artigo as teses formuladas por Daniel Stern, etólogo e psicanalista que vem se dedicando nos últimos anos a observações minuciosas dos processos primários de subjetivação das crianças, prestando uma atenção especial ao tema da experiência afetiva. Partindo de uma breve localização do lugar dos afetos em sua teoria, passamos a uma apresentação da forma temporal dos sentimentos no contexto das relações interpessoais para, em seguida, discutirmos dois dos principais conceitos formulados por ele, quais sejam, os de afeto de vitalidade e sintonia afetiva. Durante esse percurso também serão rapidamente abor- 
dados outros temas relevantes, tais como as noções de interação afetiva, empatia e comunicação emocional.

\section{Afeto e afetividade na obra de Daniel Stern}

De acordo com Félix Guattari, na via de uma compreensão polifônica e heterogenética da subjetividade, Stern explorou notavelmente as formações subjetivas pré-verbais da criança. Ele mostra que, nesse caso, não se trataria estritamente de "fases", no sentido freudiano clássico, mas de níveis de subjetivação que se manterão paralelos ao longo da vida. Nesses termos, ele renuncia ao caráter superestimado da psicogênese dos complexos freudianos que foram apresentados como "universais" estruturais da subjetividade. Por outro lado, valoriza o caráter trans-subjetivo, desde o início das experiências precoces da criança, que não dissocia o sentimento de si do sentimento do outro."Uma dialética entre os 'afetos partilháveis' e os 'afetos não partilháveis' estrutura, assim, as fases emergentes da subjetividade. Subjetividade em estado nascente que não cessaremos de encontrar no sonho, no delírio, na exaltação criadora, no sentimento amoroso" (Guattari, 1992, p. 16).

Segundo Spezzano (1993), Stern foi além de todos os observadores de bebês anteriores, ao sustentar não apenas que os pesquisadores da infância observam os bebês, mas afirmando que eles "conversam" com eles. Desse ponto de vista, os bebês supostamente estão contando aos experimentadores sobre os seus próprios processos mentais. Argumentando que os bebês constroem memórias prototípicas e representações mentais a partir de múltiplas experiências visuais experimentalmente manipuladas, ele afirma que seria justo admitir que eles fizessem o mesmo com "experiências afetivamente vividas".

Já para Fonagy, Gergely, Jurist e Target (2004), Stern adota uma posição "intersubjetivista forte", a qual afirma (a) que os bebês humanos nascem com mecanismos inatos para identificar e atribuir estados mentais à mente do outro, tais como intenções ou sentimentos, durante interações sociais precoces e contingentes; (b) que desde o início da vida existe um conjunto relativamente rico de estados mentais diferenciados do self tais como emoções, intenções, motivos e objetivos que são introspectivamente acessíveis ao bebê;e (c) que tais estados mentais subjetivos do self podem ser reconhecidos como similares aos estados mentais correspondentes do outro e, enquanto tais, são experienciados como"compartilhados"com ele.

\section{Processo interpessoal e formas temporais de sentimento}

Em termos ainda gerais, diríamos que Stern parte do pressuposto de que a vida sem afeto seria tão difícil de imaginar como a vida sem 
cognição. Considerando o fato de que todos os incidentes se desdobram no tempo, ele afirma que o comportamento humano está quase sempre mudando, e mesmo as experiências interiores de excitação e de afeto sofrem alterações momentâneas de intensidade e de direção. $O$ sorriso de uma mãe, por exemplo, é um caso a considerar. Será que o bebê sente e percebe aquele sorriso como uma imagem fixa, uma fotografia, ou como uma sequência de movimento de curta duração, padronizada no tempo e no espaço, como as imagens de um filme? Do ponto de vista dele, a experiência dos sons, e talvez dos sentimentos interiores, só é possível no decurso do tempo, indicando que uma "fatia" instantânea de som ou de afeto não comporta nenhum significado coerente ou forma reconhecível. Sendo assim, pode-se suspeitar que o mesmo aconteça na percepção de sorrisos e de outros comportamentos humanos visualizados.

Ao discorrer sobre $A$ primeira relação mãe-bebê, o autor sugere que

pelo menos no campo interativo do comportamento humano, existe uma unidade básica de processamento da experiência interativa. Esta unidade de processamento, não é necessariamente a menor unidade perceptiva de qualquer modalidade, mas, pelo contrário, é a menor unidade em que é possível acontecer um incidente temporalmente dinâmico, com princípio, meio e fim. Tal unidade de processamento é como o incidente mais breve, ou vinheta, que pode conter um elemento da experiência sensorial, motora e afetiva e, assim, ter valor sinalizador como acontecimento interpessoal. (Stern, 1977, p. 111)

Essas unidades de processo interpessoal podem ser unidades da experiência sensorial-motora-afetiva, inicialmente intermalizadas como representações separadas e que, depois de integradas, formam a representação mais ampla de outra pessoa.

Conforme dissemos antes, Stern faz questão de ressaltar a importância de lembrarmos que, quando experienciamos afetos, assim como quando experienciamos uma música, estamos "no tempo", no fluxo do tempo. Trata-se de uma experiência temporal na qual as mudanças, desdobrando-se no presente, criam a experiência. Infelizmente, muitas vezes, quando falamos de afetos esquecemo-nos de que eles só são experienciados no tempo. E é exatamente por isso que não se pode cortar uma pequena fatia temporal - como uma fotografia o faz - de uma frase musical nem de um sentimento, sem destruir o todo. No entanto, muitas vezes agimos como se a experiência não tivesse nenhuma extensão temporal, ou consideramos que o aspecto temporal está adequadamente coberto pela sequência dos acontecimentos; mas os acontecimentos, em si mesmos, não são considerados em termos temporais. Talvez por essas razões negligenciemos em grande medida a ideia de que os contornos temporais proporcionam a espinha dorsal que permite que as experiências afetivas sejam representadas. 
Mais especificamente, sempre que um motivo é encenado (iniciando-se interna ou externamente, como beber quando se tem sede ou receber e adaptar-se a más notícias), necessariamente ocorrem mudanças no que se refere ao prazer, à excitação, ao nível de motivação ou à consecução de um objetivo, as quais acompanham a encenação. Em seu trabaIho sobre $A$ constelação da maternidade, o autor nos mostra que

\begin{abstract}
estas mudanças desdobram-se no tempo e cada uma descreve um contorno temporal. Os contornos temporais agem em comum acordo e parecem ser subjetivamente experienciados como um único sentimento complexo que é uma combinação (uma "propriedade emergente") dos contornos temporais individuais de hedonia, excitação e motivação. Esta é a forma temporal de sentimento, a que chamarei de forma de sentimento, para abreviar. A forma de sentimento também incluirá a qualidade específica do sentimento que recebe temporariamente um contorno. E isso dependerá de quais afetos e motivações estão envolvidos. (Stern, 1995, p. 84, itálicos do autor)
\end{abstract}

Nesses termos, a forma temporal proporciona o enquadre estrutural no qual o sentimento assume sua forma e pode ser representado. A forma temporal de sentimento é uma curva ou unidade de experiência afetiva que pode estar inserida em formas de sentimento mais amplas (isto é, mais longas ou complexas). Ela pode então ser vista como um formato representacional plausível para esquematizar a experiência afetiva.

De acordo com Golse (2003), as formas de sentimento descritas por Stern no quadro das interações precoces constituem verdadeiras linhas emocionais e temporais. Elas permitem um reconhecimento e um investimento do objeto pela via de seus contornos rítmicos e interativos (estilo interativo e características de sintonia afetiva, discutida mais adiante neste artigo), antes mesmo que o bebê possa reconhecê-lo pelas suas especificidades formais e estatísticas.

O bebê e o cuidador contribuem em conjunto para a regularização do estado de atenção, excitação e afeto do bebê. Do ponto de vista do bebê, essas poderosas sensações e alterações internas provavelmente não são experienciadas como pertencendo exclusivamente à estimulação por parte do cuidador (experiência sensorial), nem como uma experiência que pertença exclusivamente aos próprios atos do bebê (a experiência motora). Segundo Stern, "é mais provável que sejam para ele uma experiência composta e indiferenciada, incluindo o que o cuidador faz, o que o bebê faz, e como tudo isso é sentido interiormente"(Stern, 1977, p. 116).

\title{
O mundo dos afetos de vitalidade
}

Investigando $O$ mundo interpessoal do bebê, o autor nos chama a atenção para o fato de que há uma qualidade da experiência que pode 
surgir diretamente dos encontros com pessoas, uma qualidade que envolve o que ele chama de afetos de vitalidade. Esse novo termo, acrescentado para abordar certas formas da experiência humana, se faz necessário porque muitas qualidades de sensação experienciadas não se ajustam ao nosso léxico ou taxionomia de afetos existentes. Essas qualidades indefiníveis são mais bem capturadas por termos dinâmicos, cinéticos, tais como "surgindo",'desaparecendo",' passando rapidamente", "crescendo","'decrescendo","explodindo," "prolongado", etc. Essas qualidades da experiência são, com toda certeza, sensíveis para os bebês e de grande importância cotidiana.

\begin{abstract}
São essas sensações que serão eliciadas por mudanças nos estados motivacionais, apetites e tensões. A filósofa Suzanne Langer insistiu que em qualquer forma de experiência próxima à psicologia deve ser dada grande atenção às muitas "formas de sensação" inextrincavelmente envolvidas com todos os processos vitais, tais como respirar, ter fome, eliminar, adormecer ou acordar, ou sentir o ir e vir das emoções e pensamentos. (Stern, 1992, pp. 47-48)
\end{abstract}

O bebê experiencia essas qualidades interiormente, assim como no comportamento de outras pessoas. Diferentes sentimentos de vitalidade podem se expressar em inúmeros atos parentais que não se qualificam como atos afetivos "regulares". Dentre eles destacam-se a maneira como a mãe ergue o bebê, troca as fraldas, arruma seu cabelo ou o cabelo do bebê, busca a mamadeira, desabotoa sua blusa. Nessas condições, podemos supor que o bebê esteja imerso nesses "sentimentos de vitalidade".

Tendo em conta que os afetos de vitalidade são experiências subjetivas, Stern nos chama atenção mais uma vez para o fato de que eles consistem em uma dinâmica temporal de mudança nos sentimentos, comportando modificações analógicas em tempo real de afetos, pensamentos, percepções ou sensações a cada fração de segundo. Como exemplo, poderíamos citar um sentimento de aceleração e a explosão de raiva subsequente. Tais experiências em geral ocorrem em paralelo com os contornos temporais de estimulação.

\footnotetext{
Os afetos de vitalidade são experiências subjetivas. Os contornos temporais de estimulações, ao contrário, são acontecimentos objetificáveis. Há um isomorfismo incompleto entre os contornos temporais e os afetos de vitalidade. Afetos de vitalidade são sinônimo de formas temporais de sentimento, formas de sentimento ou formas temporais. (Stern, 2004, pp. 246-247)

Eles são chamados, experimentalmente, de afetos de vitalidade, nos diz o autor, para distingui-los dos "afetos categóricos" tradicionais ou darwinianos de raiva, alegria, tristeza, desgosto, vergonha, medo e surpresa, ainda que ocorram tanto na presença quanto na ausência desses
} afetos categóricos. 
A expressividade dos afetos de vitalidade, diz Stern, pode ser comparada a um show de marionetes. As marionetes possuem pouca ou nenhuma capacidade de expressar categorias de afeto através de sinais faciais, e seu repertório de sinais de afeto gestuais ou posturais convencionais usualmente é pobre. É através da maneira como elas se movem em geral que inferimos os diferentes afetos de vitalidade a partir dos contornos de ativação traçados por elas. Na maior parte das vezes, os caracteres das diferentes marionetes são largamente definidos em termos de afetos de vitalidade particulares: uma pode estar letárgica, com membros pendentes e cabeça pendurada; uma outra enérgica e ainda uma outra animada.

No entanto, a dança abstrata e a música parecem ser os exemplos, por excelência, da expressividade dos afetos de vitalidade. A dança revela ao expectador-ouvinte múltiplos afetos de vitalidade e suas variações, sem recorrer à trama ou aos sinais de afeto categórico dos quais os afetos de vitalidade podem ser derivados. O coreógrafo, na maior parte das vezes, está tentando expressar uma maneira de sentir, não um conteúdo específico de sentimento. Do ponto de vista de Stern, esse exemplo é particularmente instrutivo porque o bebê, quando observa um comportamento parental que não possui uma expressividade intrínseca (isto é, nenhum sinal de afeto darwiniano), pode estar na mesma posição do espectador de uma dança abstrata ou do ouvinte de música. A maneira como é realizado o ato de um progenitor expressa um afeto de vitalidade, seja ou não esse ato algum afeto categórico (ou parcialmente colorido por algum afeto categórico).

Podemos prontamente imaginar, de fato, que o bebê inicialmente não percebe atos manifestos como os adultos percebem. Pelo contrário, é muito mais provável que o bebê perceba diretamente e comece a categorizar os atos em termos dos afetos de vitalidade que eles expressam. Como a dança para o adulto, o mundo social experienciado pelo bebê é primariamente um mundo de afetos de vitalidade antes de ser um mundo de atos formais. Ele também é análogo ao mundo físico da percepção amodal, que é primariamente um mundo de qualidades passiveis de serem abstraídas de forma, número, nível de intensidade e assim por diante, não um mundo de coisas vistas, ouvidas ou tocadas. (Stern, 1992, pp. 49-50)

Outra razão para separar os afetos de vitalidade dos afetos categóricos é que eles não podem ser adequadamente explicados pelo conceito de nível de ativação. Na maioria dos relatos acerca dos afetos e suas dimensões, o que é chamado de afeto de vitalidade poderia ser incluído na dimensão invariável, que serve ao mesmo tempo para muitas finalidades, do nível de ativação ou excitação. Ativação e excitação certamente ocorrem, mas não são experienciadas simplesmente como sentimentos 
em algum lugar ou em algum ponto dessa dimensão. Elas são experienciadas como mudanças dinâmicas ou padronizadas dentro de nós mesmos. Podemos usar a dimensão de excitação-ativação apenas como um índice geral de nível de excitação-ativação. Precisamos acrescentar uma categorização inteiramente nova desse aspecto da experiência, isto é, os afetos de vitalidade que correspondem a mudanças padronizadas características. Essas mudanças, padronizadas através do tempo, ou contornos de ativação, são subjacentes aos diferentes afetos de vitalidade.

Se os bebês experienciam afetos de vitalidade, como nosso autor sugere, eles estarão com frequência em uma situação em que uma variedade de experiências sensoriais diversas com contornos de ativação similares podem ser reunidas - isto é, podem ser experienciadas como correspondentes e, dessa forma, como algo que cria uma organização.

Na medida em que o bebê avança no processo de experienciar um outro emergente, diante de uma mãe distinta que acaricia e de uma segunda mãe separada que acalma, ele irá experienciar somente um único afeto de vitalidade nas atividades tranquilizadoras - uma"mãe afetiva de vitalidade tranquilizadora. Dessa maneira, a experiência amodal dos afetos de vitalidade, assim como as capacidades para a combinação modal cruzada das formas percebidas, irá aumentar grandemente o progresso do bebê em direção à experiência de um outro emergente" (Stern, 1992, p.51).

\section{Interação, empatia e comunicação emocional}

De acordo com Peter Fonagy e colaboradores, partindo do conceito de afetos de vitalidade Stern propõe uma teoria voltada para o papel dos comportamentos parentais afetivo-reflexivos no desenvolvimento socioemocional primitivo. Ele acredita que as interações envolvendo os aparatos emotivo-reflexivos parentais têm uma influência significativa no desenvolvimento do self e na autorregulação afetiva.

Sua teoria enfoca um tipo específico de interação afetivo-reflexiva, chamada de "sintonia do afeto", comentada em detalhes mais adiante neste trabalho, que ele demonstrou ocorrer regularmente nas interações normais mãe-bebê entre nove e doze meses. Ele notou que durante as brincadeiras as mães periodicamente refletem algum aspecto das ações de seus bebês, proporcionando uma equiparação parcial do comportamento do bebê em outra modalidade. No que concerne à natureza desses atos de sintonia o autor apresenta alguns pontos interessantes, dentre os quais se destaca o fato de que eles não são simples atos de imitação, na medida em que envolvem uma equiparação apenas parcial das características amodais (temporais, de intensidade e de forma) do ato objetivo do bebê, expresso em uma modalidade diferente. 
Stern propõe que a razão pela qual por volta dos nove meses a mãe - não conscientemente - escolhe "sintonizar" com o comportamento do bebê, mais do que simplesmente proporcionar uma réplica imitativa, é que ela pretende se referir ao estado afetivo interno do bebê mais do que ao seu comportamento de superfície. Do seu ponto de vista, as características amodais equiparadas correspondem às formas representacionais abstratas dos afetos que acompanham o ato comportamental externo. Assim, a função sugerida para estas sintonias do afeto é aquela da "comunhão interpessoal": "compartiIhar" ou "participar da" experiência afetiva interna do bebê. (Fonagy et al., 2004, p. 182)

No que concerne à ideia de uma "partilha de afeto", René Roussillon chama a atenção para o fato de que o afeto experimentado pelo bebê deve ser sintonizado de forma empática pela mãe. Esta deve poder experimentar "em espelho" o afeto presente no bebê. Mais precisamente, seria necessário dizer o"afeto potencial", pois, precisamente, se o bebê é afetado por processos somáticos que buscam se fazer representar na psique, ele só pode apreendê-los na medida em que o objeto os reflete, na medida em que ele possa reencontrá-los fora.

Isso não significa que a mãe esteja no mesmo estado afetivo do bebê, mas que aquilo que ela vive está em empatia com aquilo que vive seu bebê - diríamos, com D. Stern:"no modo próximo", o que significa que há uma correspondência entre os dois modos experimentados, uma adequação e não uma identidade. (Roussillon, 2005, pp. 129-130)

Dito de outro modo, o "espelho" materno comunica ao bebê que ele "se faz de espelho", que ele "se faz de duplo". Ou ainda, isso significa que o afeto reverberado pela mãe se expressa como um "signo" de afeto e não exatamente como um afeto. A observação mostraria, além disso, que esse tipo de resposta materna - aquele no qual ela "partilha" o afeto com o bebê -, reflete para ele esse afeto e assinala que ela o faz, apaziguando o estado de "paixão" afetiva do bebê.

Referindo-se à importância da noção de empatia no trabalho de Stern, Simas e Golse consideram que as investigações do autor sobre $O$ mundo interpessoal do bebê se apoiam sobre a microanálise de sequências registradas de interações do bebê com o seu ambiente maternante, análise que recorre com frequência a uma espécie de empatia participante. Stern descreve assim a emergência precoce de um "senso de eu", experiência elementar da existência de um "self" que ele define como o sentimento de "ser ou estar com", parcialmente programados desde o nascimento, mas que vai evoluir por estágios sucessivos até o"senso de si" ou self verbal. É a partir desse modelo interno que o bebê vai formar representações do mundo social que o cerca: entre o segundo e o sexto mês de vida ele começa a constituir uma representação do "laço inter- 
pessoal", quando ele sente sua mãe e a si mesmo como completamente distintos em termos físicos.

\begin{abstract}
A importância dos sinais de ordem emocional sublinha ao mesmo tempo a importância da dimensão relacional e afetiva como codeterminante do desenvolvimento... As competências aí colocadas em evidência são adquiridas pelo bebê a partir da experiência das trocas com os humanos que o cercam... Neste contexto é fundamental levar em conta o fato de que são, antes de tudo, afetos, sentimentos, emoções que estão em jogo na comunicação e nas interações colocadas em ação desde as primeiras horas da vida. (Simas \& Golse, 2008, p. 263)
\end{abstract}

Stern nos mostra particularmente bem como esses afetos são partilhados no processo de sintonia entre o bebê e seu ambiente maternante, e também mostra como essas trocas se inscrevem em uma trama narrativa introduzindo o bebê em uma dimensão de temporalidade e causalidade.

Considerando que a relação mãe-bebê implique em educar os sentimentos e co-construir afetos, Golse afirma ainda que a comunicação emocional e a interação afetiva se fundam precisamente sobre contornos rítmicos e dinâmicos de sintonia afetiva, processos que se encontram na base do que ele chama de harmonização dos afetos.

A sintonia afetiva vale, nos parece, como função especular micro-comportamental dado que oferece à criança uma sinalização em eco, um espelho de sua própria vivência emocional ou afetiva, e essa permite um acesso a si mesmo pela via do outro (desvio pelo outro, sobre o qual insistiram alguns autores como Winnicott, Bion e mesmo Green). (Golse, 2003, p. 119)

\title{
O compartilhar através da sintonia do afeto
}

A interafetividade, do ponto de vista de Stern, pode ser considerada a forma primeira, mais difundida e mais fundamentalmente importante de compartilhar experiências afetivas. Cedo na vida, os afetos são tanto o meio primário como o assunto primário da comunicação. Dos nove aos doze meses, quando o bebê começou a compartilhar ações e intenções com relação a objetos e a trocar proposições de forma prélinguística, a troca afetiva ainda é o modo e a substância predominantes das comunicações com a mãe. É por essa razão que o compartilhar dos estados afetivos merece uma ênfase primária na análise visão de bebês dessa idade. A maioria das trocas protolinguísticas envolvendo intenções e objetos no mundo interpessoal do bebê são, ao mesmo tempo, trocas afetivas. As duas coisas acontecem simultaneamente e os achados que definem um determinado evento como primariamente linguístico ou 
primariamente afetivo dependem da perspectiva. Contudo, o bebê que está aprendendo o modo discursivo parece ser bem mais perito no domínio da troca de afeto. De modo semelhante, o compartilhar dos humores e estados afetivos aparece antes do compartilhar de estados mentais que referenciam objetos, isto é, coisas fora da díade. Do ponto de vista de Stern parece claro que o compartilhar dos estados afetivos é de imensa importância durante a primeira parte do relacionar-se intersubjetivo.

O compartilhar dos estados afetivos é o aspecto mais universal e clinicamente relevante do relacionar-se intersubjetivo. Isso é especialmente verdadeiro quando o bebê entra, pela primeira vez, nesse domínio. A interafetividade é principalmente aquilo que os terapeutas querem dizer quando falam do "espelhar" parental e da "responsividade empática". Os bebês dos quais estamos falando estão apenas entre os nove e quinze meses de idade. (Stern, 1992, p. 123)

Conforme mencionávamos acima, para que haja uma troca intersubjetiva em relação ao afeto, apenas uma imitação exata não funciona. Primeiramente o progenitor deve ser capaz de ler o estado de sentimento do bebê a partir de seu comportamento manifesto. Além disso, o progenitor deve realizar algum comportamento que não seja uma imitação exata, mas que, não obstante, corresponda de alguma forma ao comportamento manifesto do bebê.Por último, o bebê deve ser capaz de ler essa resposta parental correspondente como tendo a ver com a sua experiência de sentimento original e não apenas como uma imitação de seu comportamento. É apenas na presença dessas três condições que os estados de sentimento dentro de uma pessoa podem ser reconhecíveis para outrem e que ambos podem sentir, sem usar a linguagem, que uma transação ocorreu.

Para realizar essa transação, a mãe deve ir além das imitações exatas que foram uma parte enorme e importante de seu repertório social durante os primeiros seis meses de vida do bebê aproximadamente. Vários investigadores descreveram em detalhes como os cuidadores e bebês criam mutuamente as cadeias e sequências dos comportamentos recíprocos que formam os diálogos sociais durante os primeiros nove meses do bebê. $O$ que chama a atenção nessas descrições é que a mãe está quase sempre funcionando na mesma modalidade do bebê. E nas orientações, seguimentos, esclarecimentos e elaborações que formam a sua parte do diálogo, ela geralmente está fazendo imitações rigorosas ou livres do comportamento imediato do bebê. No entanto, esse diálogo não permanece uma sequência estereotípica aborrecida de repetições, de um lado para outro, porque a mãe está constantemente introduzindo imitações modificadoras ou oferecendo um formato de tema e variação com leves mudanças na sua contribuição em cada momento dialógico. 
Quando o bebê está com cerca de nove meses, nos diz Stern, começamos a ver que a mãe acrescenta uma nova dimensão ao seu comportamento de imitação, uma dimensão que parece se ajustar ao novo status do bebê como um parceiro potencialmente intersubjetivo. Ela começa a expandir seu comportamento, além da simples imitação ${ }^{2}$, para uma nova categoria de comportamento que o autor chama de "sintonia do afeto".

Essa sintonia afetiva é uma forma especial de comportamento em resposta ao comportamento afetivo comunicativo de outrem. Assim como a imitação é uma versão fiel das ações abertas do outro, a sintonia afetiva é uma versão fiel do que o outro deve ter sentido quando se expressou através daquelas ações. Isso requer que a sintonia imite apenas a dinâmica temporal da intensidade, da forma ou do ritmo do comportamento do outro, mas numa modalidade ou escala diferente.

Desse modo, as ações reais do outro não se tornam o referente da sintonia (como ocorreria na imitação); na verdade, o sentimento por trás das ações se torna o referente. Trata-se de uma forma de imitar, a partir do interior, como parece ser uma experiência, e não como ela foi expressa numa ação. (Stern, 2004, p. 241)

Em seu Diário de um bebê, Stern nos mostra que, evitando uma imitação fiel, a mãe cria intuitivamente essa imitação cuidadosamente selecionada e elaborada que é a sintonia. Ela toma aquelas partes do que o bebê fez que melhor refletem o seu sentimento interior e altera aquelas partes que eram específicas à modalidade de expressão do filho.Com isso, por exemplo, ela substituiu uma alteração no tom por uma alteração no aspecto, uma expressão facial por uma vocal. Ao conseguir falar ao sentimento interno do bebê enquanto avalia seu comportamento manifesto, ela não pode ser propriamente confundida apenas com um espeIho. Somente um ser humano que sabe o que o bebê sentiu pode emitir uma expressão vocal que seria análoga e não uma cópia de sua experiência, o que faz com que o bebê entenda que sua mensagem chegou à mãe. Esse tipo de correspondência analógica ocorre fora da consciência, como uma manifestação especial de empatia. "A maioria de nós faz isso intuitivamente. $E$ o filho de pais que por qualquer razão não conseguem

2 A discussão sobre o papel da imitação na gênese dos processos de subjetivação aparece em contextos teóricos que buscam explicar os processos de estruturação da representação (cf. Piaget, 1975; Piaget e Inhelder, 1980; Wallon, 1979, 1986). Quanto a isso, nota-se uma dificuldade com relação a um acordo conceitual sobre o que é a imitação. Wallon (1979) coloca o problema chamando a atenção para duas formas distintas de conceituá-la. A primeira diz que ela é um ato que reproduz um modelo, mas isso implicaria em admitir uma representação anterior ao ato imitativo. A segunda refere-se à semelhança entre dois atos, se os seus protagonistas estiverem em situação de observação mútua. Para maiores esclarecimentos sobre essa questão, ver Pedrosa (1994). 
fazer isso ou sentem-se inibidos para fazê-lo, se sentirá fisicamente mais solitário com esta pessoa e talvez, em última análise,com o mundo"(Stern, 1992, p. 92).

Deixando que uma vocalização sua penetre no filho para ver se corresponde ao sentimento interno que ele recém experimentou, a mãe faz com que o bebê perceba que compartilha seu sentimento. Ele sabe que a resposta vocal da mãe corresponde ao seu sentimento porque pode traduzir de uma modalidade sensorial para outra. Ele também sabe que um formato de onda crescente e decrescente no tom de voz é o mesmo formato que apresenta no rosto de outra pessoa ou no tom emocional experimentado em algum lugar dentro de si mesmo. Ele, portanto, reconhece a autenticidade da resposta de sua mãe.

Nesses termos, pode-se dizer que a mãe carrega sua palavra afetivamente e a destaca do usual afim de que o bebê reflita e reaja a ela.

Temos aí uma espécie de "momento presente". Ele terá criado um "momento de encontro", um daqueles nos quais os dois domínios de conhecimento terão sido transformados. Seu conhecimento explícito [o do bebê] foi enriquecido por uma palavra nova. E seu conhecimento implícito do espaço intersubjetivo que ele ocupa com sua mãe foi modificado, porque ele sabe agora que ele e ela partilham esta realidade subjetiva. (Stern, 1997, p. 54)

Nesse caso estamos diante de um novo estado intersubjetivo.

Em um momento fundamental como esse o bebê e sua mãe compartilharam um sentimento. Segundo Stern, a implicação desses acontecimentos é grande. Esse compartilhamento é a base para os aspectos posteriores da intimidade psíquica. $\mathrm{O}$ mundo interior pode e deve ser mostrado e compartilhado, tendo em conta que a profundidade da intimidade psíquica com a qual finalmente o bebê se sentirá confortável está sendo estabelecida. $O$ bebê e sua mãe estão no processo de decidirem os limites do universo compartilhável de sentimentos. Juntos, eles estabeleceram que uma onda de prazer é um evento interno que podem compartilhar. Ele agora pertence aos dois.

Investigando esse mundo intersubjetivo do bebê podemos notar que as sintonias têm as seguintes características, que as tornam ideais para que se consiga o compartilhar intersubjetivo do afeto: (1) dão a impressão de que ocorreu algum tipo de imitação. Não há uma reprodução fiel do comportamento manifesto do bebê, mas alguma forma de equiparação está se processando; (2) a equiparação é, em grande parte, modalcruzada. Isto é, o canal ou modalidade da expressão usada pela mãe para se equiparar ao comportamento do bebê é diferente do canal ou modalidade usado por ele; (3) o que está sendo igualado não é o comportamento da outra pessoa, em si, mas, ao contrário, algum aspecto do comportamento que reflete o estado de sentimento da pessoa. A referência 
fundamental para a equiparação parece ser o estado de sentimento (inferido ou diretamente percebido), e não o evento comportamental externo. Assim, a equiparação parece ocorrer entre as expressões de estado interno. Essas expressões podem diferir em modo ou forma, mas são até certo grau intercambiáveis como manifestações de um estado interno reconhecível simples. Parece que estamos lidando com o comportamento como expressão. A sintonia do afeto, para Stern, é o desempenho de comportamentos que expressam a qualidade do sentimento de um estado afetivo compartilhado, sem imitar a exata expressão comportamental do estado interno.

A sintonia do afeto é uma forma particular de intersubjetividade que requer alguns processos que são únicos para ela.

"Espelhar" e "ecoar" representam os termos e conceitos clínicos que mais se aproximam da sintonia do afeto. Esses conceitos representam tentativas de enfrentar a questão de uma pessoa refletindo o estado interno de outra. Nesse importante aspecto, diferente da imitação ou do contágio, eles se referem apropriadamente ao estado subjetivo e não ao comportamento manifesto. (Stern, 1992, p. 128)

Refletir de volta o estado de sentimento de um bebê é importante para que ele desenvolva o conhecimento de sua própria afetividade e senso de eu.

A existência de uma sintonia é, à primeira vista, uma impressão clínica, talvez uma intuição. Para operacionalizar essa impressão é necessário identificar aqueles aspectos do comportamento de uma pessoa que poderiam ser igualados sem que realmente fossem imitados. De acordo com Stern, existem três aspectos gerais de um comportamento que poderiam ser igualados (e assim formar a base de uma sintonia) sem que fosse feita uma imitação. Eles são a intensidade, o timing e a forma. Essas dimensões foram divididas em seis tipos de equiparação mais específicos:

(1) Intensidade absoluta - o nível de intensidade do comportamento da mãe é o mesmo que o do bebê, independentemente do modo ou forma de comportamento; (2) Contorno de intensidade - as mudanças de intensidade no tempo são igualadas; (3) Batida temporal - uma pulsação regular, no tempo, é igualada; (4) Ritmo - um padrão de pulsações de ênfase desigual é igualado; (5) Duração - o período de tempo do comportamento é igualado. Se os comportamentos da mãe e do bebê duram mais ou menos o mesmo tempo, ocorreu uma equiparação da duração; (6) Forma - algum aspecto espacial de um comportamento, que pode ser abstraído e remodelado em um ato diferente é igualado. (Stern, 1992, p. 130)

É bastante fácil determinar que as sintonizações e más sintonias influenciam o bebê: elas normalmente resultam em alguma alteração ou 
interrupção do comportamento do bebê em um dado momento. A situação com as sintonias de comunhão é diferente. Na maioria dos casos, depois de a mãe ter feito essa sintonia, o bebê age como se nada de especial tivesse acontecido. A comunhão interpessoal criada pela sintonia desempenhará um papel importante para que o bebê venha a conhecer aqueles estados de sentimento internos como formas da experiência humana que são compartilháveis com outros seres humanos. O reverso também é verdadeiro: estados de sentimento que nunca são sintonizados serão experienciados apenas sozinhos, isolados do contexto interpessoal da experiência compartilhável. O que está em questão aqui não é nada menos do que a configuração e a extensão do universo interno compartilhável.

Para que a sintonia funcione, diferentes expressões comportamentais, ocorrendo em diferentes formas e em diferentes modalidades sensórias devem, de alguma maneira, ser intercambiáveis. Para o autor, do mundo interpessoal do bebê, se um determinado gesto da mãe pretende ser "correspondente" a um tipo de exclamação vocal do bebê, as duas expressões devem compartilhar alguma matéria comum que lhes permita serem transferidas de uma modalidade ou forma para uma outra. Essa circulação comum consiste em propriedades amodais.

\begin{abstract}
Existem algumas qualidades ou propriedades que são tidas em comum pela maioria ou por todas as modalidades de percepção. Elas incluem intensidade, forma, tempo, movimento e número.Tais qualidades de percepção podem ser abstraídas por qualquer modo sensório das propriedades invariantes do mundo dos estímulos e então traduzidas em outras modalidades de percepção. (Stern, 1992, p. 135)
\end{abstract}

\title{
Sintonizando com os afetos de vitalidade
}

Para concluir, diríamos que ambas as formas de afeto a que nos referimos no decorrer deste artigo - afetos categóricos distintos como tristeza e alegria, assim como os afetos de vitalidade como explosões e desvanecimentos - são sintonizadas no contexto das trocas entre a mãe e seu bebê que se encontram na gênese dos processos de subjetivação. De fato, no entanto, a maioria das sintonias parece ocorrer com os afetos de vitalidade.

Identificamos os afetos de vitalidade como aquelas qualidades dinâmicas, cinéticas do sentimento, que distinguem o animado do inanimado e que correspondem às mudanças momentâneas nos estados de sentimento envolvidos nos processos orgânicos de se estar vivo. Experienciamos os afetos de vitalidade como mudanças dinâmicas ou mudanças padronizadas dentro de nós mesmos ou dos outros. Uma das razões pelas quais Stern parece ter se empenhado tanto para estabelecer 
os afetos de vitalidade como entidades em si mesmas, distintos do que usualmente se quer dizer com ativação e distintos das categorias de afeto, é que eles são essenciais para um entendimento da sintonia.

Durante uma interação mãe-bebê média, manifestações de afeto distintas ocorrem apenas ocasionalmente. Uma vez que é assim, o alinhamento ou sintonia afetiva com um outro não poderia ocorrer como um processo contínuo se estivesse limitado a afetos categóricos. Não podemos esperar que ocorra uma manifestação de afeto categórico distinto, tal como uma expressão de surpresa, para podermos restabelecer a sintonia. A sintonia parece mais um processo ininterrupto. Ela não pode esperar erupções de afeto distintas; ela deve ser capaz de funcionar virtualmente com todos os comportamentos. E essa é uma das grandes vantagens dos afetos de vitalidade. Eles estão manifestos em todos os comportamentos e assim podem ser um objeto quase onipresente de sintonia.

Portanto, considerando a perspectiva de Stern, os afetos de vitalidade devem ser acrescentados às categorias de afeto como um dos tipos de estados internos subjetivos que podem ser referenciados em atos de sintonia. A vitalidade serve perfeitamente para ser o objeto das sintonias, pois ela é composta das qualidades amodais de intensidade e tempo, porque está presente virtualmente em qualquer comportamento que alguém possa realizar,e assim oferece um objeto continuamente presente (embora mutante) para a sintonia. Alinhamento e sintonia com os afetos de vitalidade permitem a um ser humano "estar com" um outro, no sentido de compartilhar experiências internas em base quase contínua. E é essa exatamente a nossa experiência primária de nos sentirmos conectados com o mundo, de estarmos em sintonia com a vida.

The place of the affective experience in the genesis of the subjectivation processes

\begin{abstract}
Given the importance and the relevance of the affects in the genesis of the subjectivation processes, this article has as its central objective to discuss the theses formulated by Daniel Stern, author who has focused, in recent years, detailed comments on the primary processes of subjectivation of the infant, giving a special attention to the subject of the affective experience. Starting from a localization of the affects in his theory, we discuss the temporal form of feelings in the context of the interpersonal relations, to discuss then two of the main concepts formulated by him: vitality affects and the affective attunement. Throughout this discussion other relevant subjects will also be contemplated, such as the notions of affective interaction, empathy and emotional communication.
\end{abstract}

Keywords: Affection. Subjectivation. Attunement. Vitality. 


\section{La place de l'expérience affective dans la genèse des processus de subjectivation}

Résumé:Donnée actualité et l'importance des affections dans la gênese des processus de subjectivation, cet article a comme objectif central discuter les thèses formulées par Daniel Stern, auteur qui vient se consacrant ces dernières années à des commentaires minutieux des procédures primaires de subjectivation de l'infant, en prêtant une attention spéciale au sujet de l'expérience affective. En partant d'une localisation des affections dans sa théorie, nous passons à une discussion à propos de la forme temporel des sentiments dans le contexte des relations interpersonnelles, pour alors analyser deux des principaux concepts formulés par lui, c'est-à-dire, les affections de vitalité et la syntonie affective. Au long de cette discussion aussi seront envisagés autres sujets importants, tels comme les notions d'interaction affective, l'empathie, et la communication émotionnelle.

Mots-clés: Affection. Subjectivation. Syntonie.Vitalité.

\section{El lugar de la experiencia afectiva en la génesis de los procesos de subjetivación}

Resumen:Dada la actualidad y la importancia del afecto en la génesis de los procesos de subjetivación, este artículo tiene como objetivo central discutir las tesis formuladas por Daniel Stern, autor que viene en estos últimos años se dedicando a comentarios minuciosos de los procesos primarios de subjetivación del infante, dando una atención especial al tema de la experiencia afectiva. Partiendo de una localización del afecto en su teoría, pasamos a una discusión a propósito de la forma temporal de los sentimientos en el contexto de las relaciones interpersonales, para después analizar dos de los conceptos principales formulados por él, que son el afecto de vitalidad y la sintonía afectiva. A través de esta discusión otros temas relevantes también serán contemplados, por ejemplo, las nociones de interacción afectiva, de empatía y de comunicación emocional.

Palabras clave: Afecto. Subjetivación. Sintonía. Vitalidad.

\section{Referências}

Fonagy, P., Gergely, G., Jurist, E., \& Target, M. (2004). Affect regulation, mentalization, and the development of the self. New York:Other. 
Golse, B. (2003). Sobre a psicoterapia pais-bebê: narratividade, filiação e transmissão. São Paulo: Casa do Psicólogo.

Green, A. (1982). O discurso vivo: uma teoria psicanalítica do afeto. Rio de Janeiro: Francisco Alves.

Guattari, F. (1992). Caosmose: um novo paradigma estético. São Paulo: Ed. 34.

Imbasciati, A. (1998). Afeto e representação. São Paulo: Ed. 34.

Manning. A. (1979). Introdução ao comportamento animal. Rio de Janeiro: LTC.

Pedrosa, M. I. (1994). A imitação como um processo de construção de significados compartilhados. Temas em Psicologia, 2(2), 111-121.

Piaget, J. (1975). A formação do símbolo na criança. Rio de Janeiro: Zahar.

Piaget, J., \& Inhelder, B. (1980). A psicologia da criança. São Paulo: Difel.

Plutchik, R., \& Kellerman, H. (1985). Emotion:Theory, research and experience. New York: Academic Press.

Roussillon, R. (2005). Affect inconscient, affect-passion et affect-signal. In J. Boushira \& H. Parat, L'Affect - monographies de psychanalyse de la revue française de psychanalyse (pp. 117-136). Paris: PUF.

Simas, R., \& Golse, B. (2008). La bouche et l'oralité dans le développement: entre explorations et ressenti, entre cognitions et émotions. In B. Golse (Org.), Le développement affectif et intellectuel de l'enfant (pp.247-256). Paris:Masson.

Spezzano, C. (1993). Affect in psychoanalysis: A clinical synthesis. London: The Analytic Press.

Stern, D. (1977). The first relationship: Infant and mother. London: Fontana Open Books.

Stern, D. (1991). Diário de um bebê.Porto Alegre: Artes Médicas.

Stern, D. (1992). O mundo interpessoal do bebê. Porto Alegre: Artes Médicas.

Stern, D. (1995). The motherhood constellation: A unified view of parent-infant psychotherapy. New York : Basic Books.

Stern, D. (1997). Le processus de changement therapéutique. In Naissance et développement de la vie psychique (pp. 39-56). Paris: Érès. 
Stern, D. (2004). The present moment in psychotherapy and everyday life. New York: Norton \& Company.

Wallon, H. (1979). Do acto ao pensamento: ensaios de psicologia comparada. Lisboa:Moraes.

Wallon, H. (1986). O papel do outro na consciência do eu.In W.J.Werebe \& J.NadelBruifert (Orgs.), Henri Wallon (pp. 113-125). São Paulo: Ática. 
Carlos Augusto Peixoto Junior, Professor Assistente do Programa de Pós-graduação em Psicologia Clínica da Pontifícia Universidade Católica do Rio de Janeiro - PUCRio. Endereço para correspondência: Rua Belisario Távora 521/102. Rio de Janeiro, RJ, Brasil.CEP 22245-070.Endereço eletrônico:cpeixotojr@terra.com.br

Márcia Arán, Professora Adjunta do Instituto de Medicina Social da Universidade do Estado do Rio de Janeiro- UERJ. Endereço para correspondência: Rua São Francisco Xavier 524, $7 \circ$ andar, sala 707. Rio de Janeiro, RJ, Brasil. CEP 20550-900. Endereço eletrônico:marciaaran@terra.com.br

Recebido: 13/10/2010

Aceito:22/06/2011 